\title{
Correction to: Análisis Regional En Ecosistemas De Montaña En Colombia: Una mirada desde la funcionalidad del paisaje y los servicios ecosistémicos
}

Paola Isaacs-Cubides, Julián Díaz, and Tobias Leyva-Pinto

\section{Correction to:}

Chapter 3 in: R. W. Myster (ed.), The Andean Cloud Forest, https://doi.org/10.1007/978-3-030-57344-7_3

This book was inadvertently published without the updated Figures 3.3, 3.5, 3.9, $3.10,3.11,3.12$ and 3.13 (mentioned below) in chapter 3. This is now updated and corrected. 


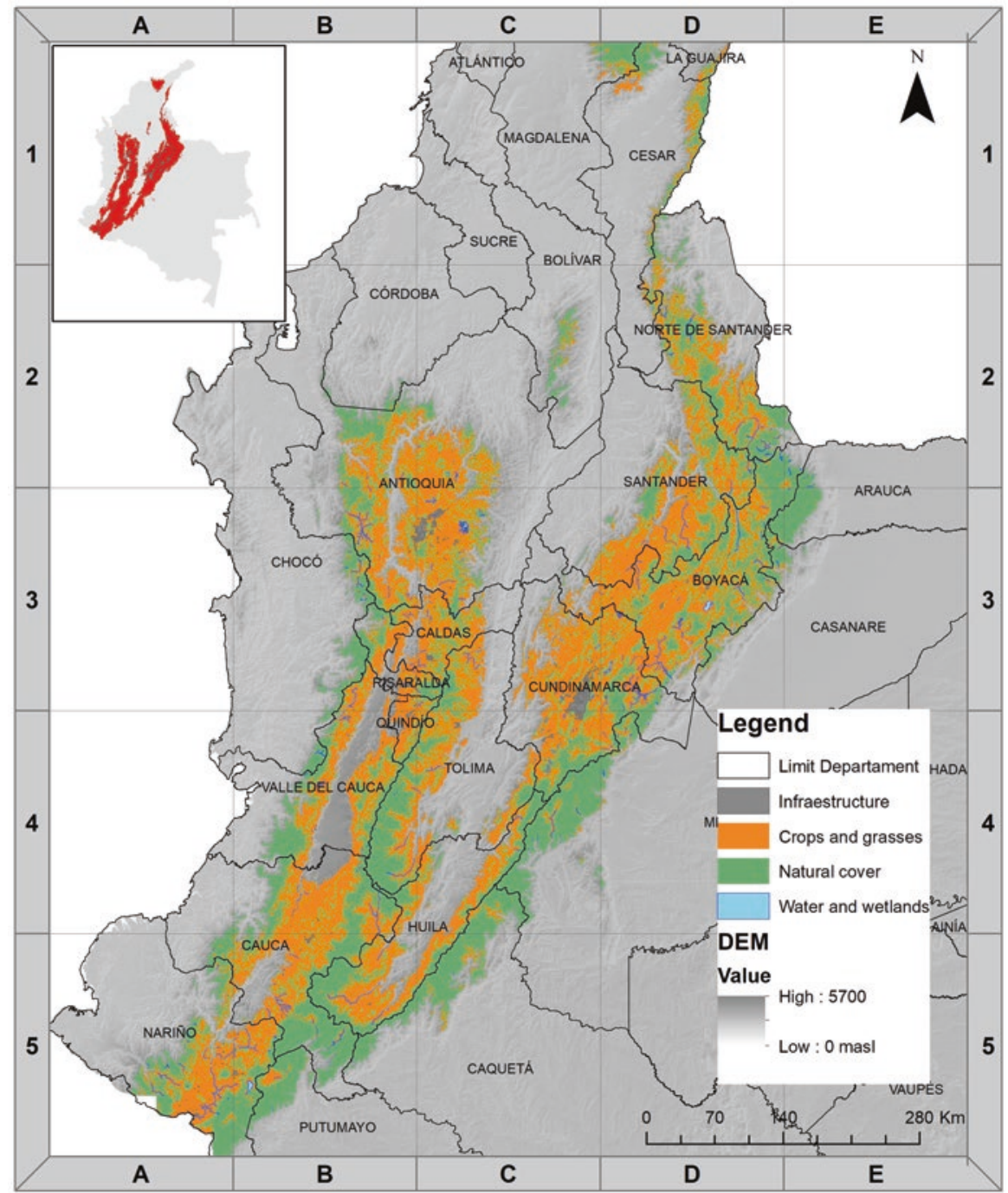

Fig. 3.3 Distribución de las coberturas presentes en las zonas de montaña 


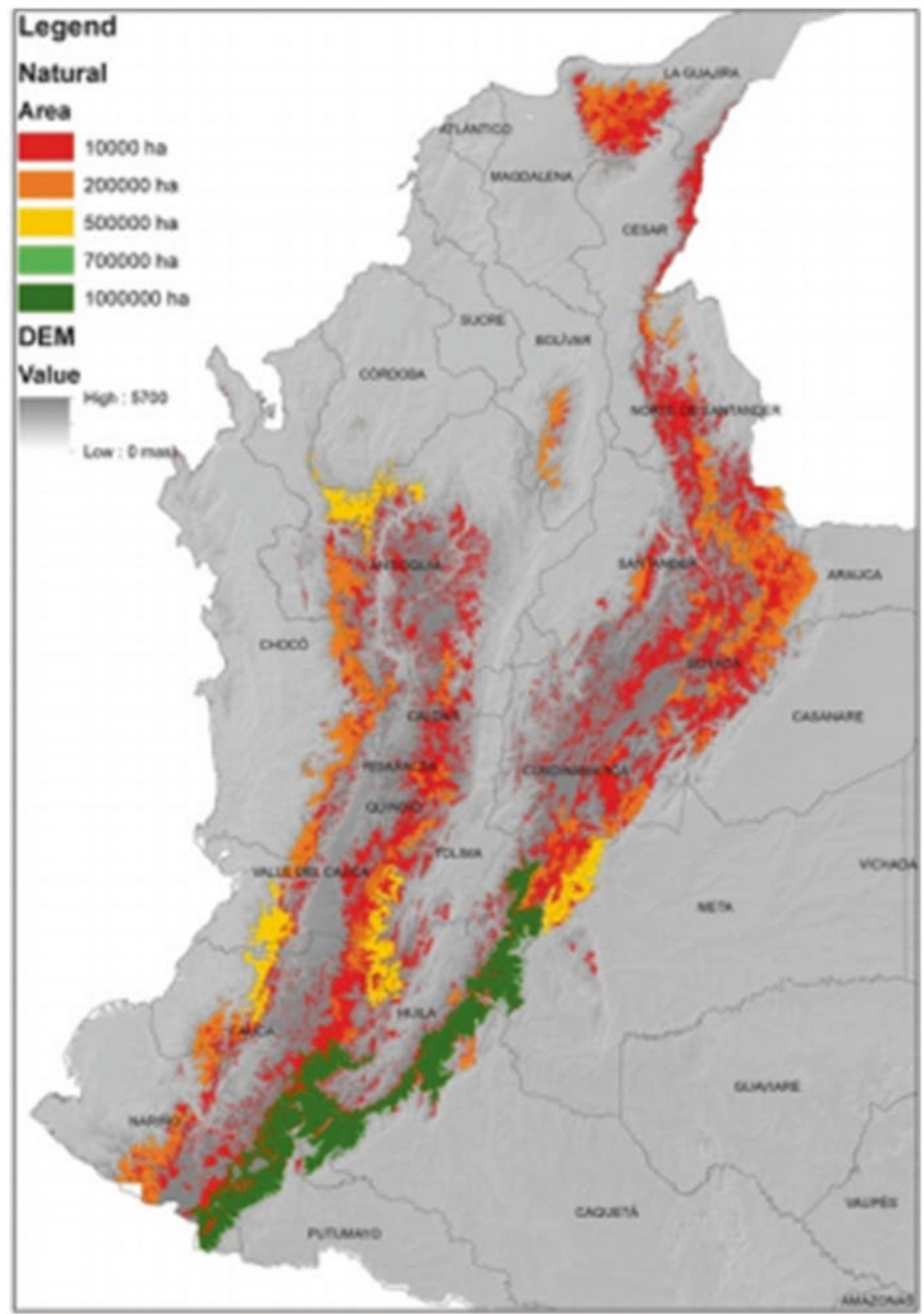

Fig. 3.5 Distribución por tamaños de las coberturas naturales 


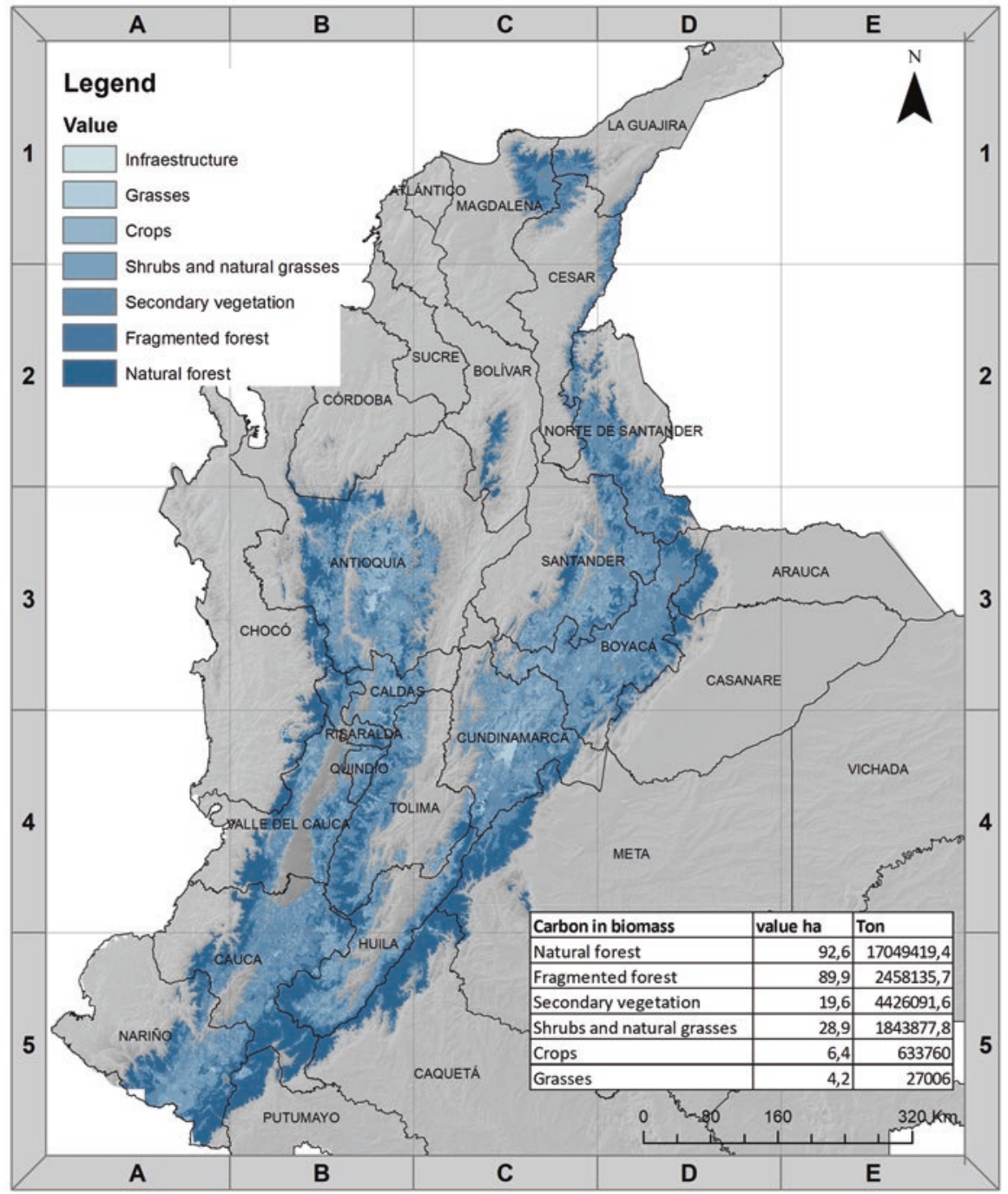

Fig. 3.9 Acumulación de carbono en biomasa, de acuerdo a los tipos de cobertura 


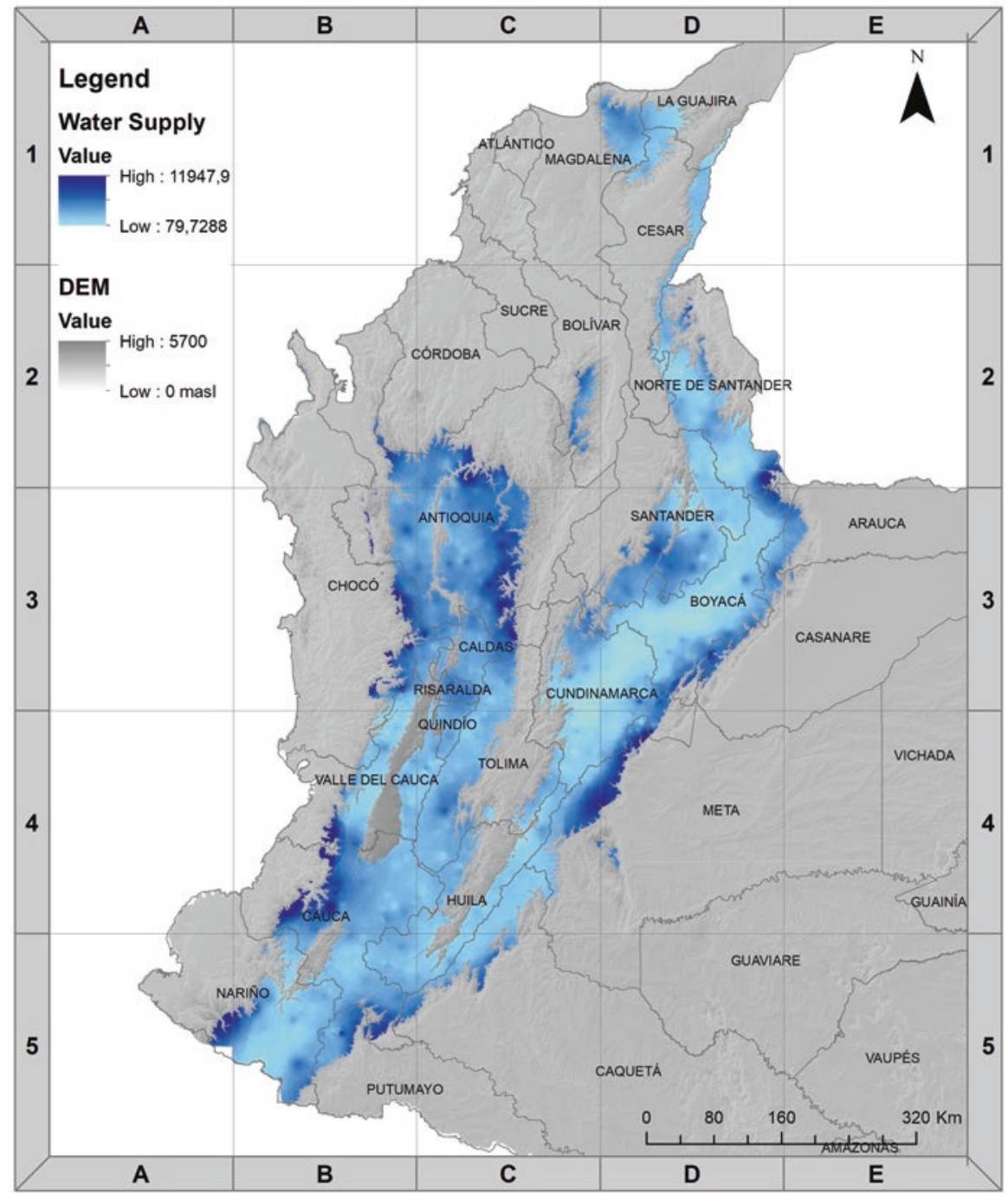

Fig. 3.10 Oferta hídrica calculada para las zonas de montaña 


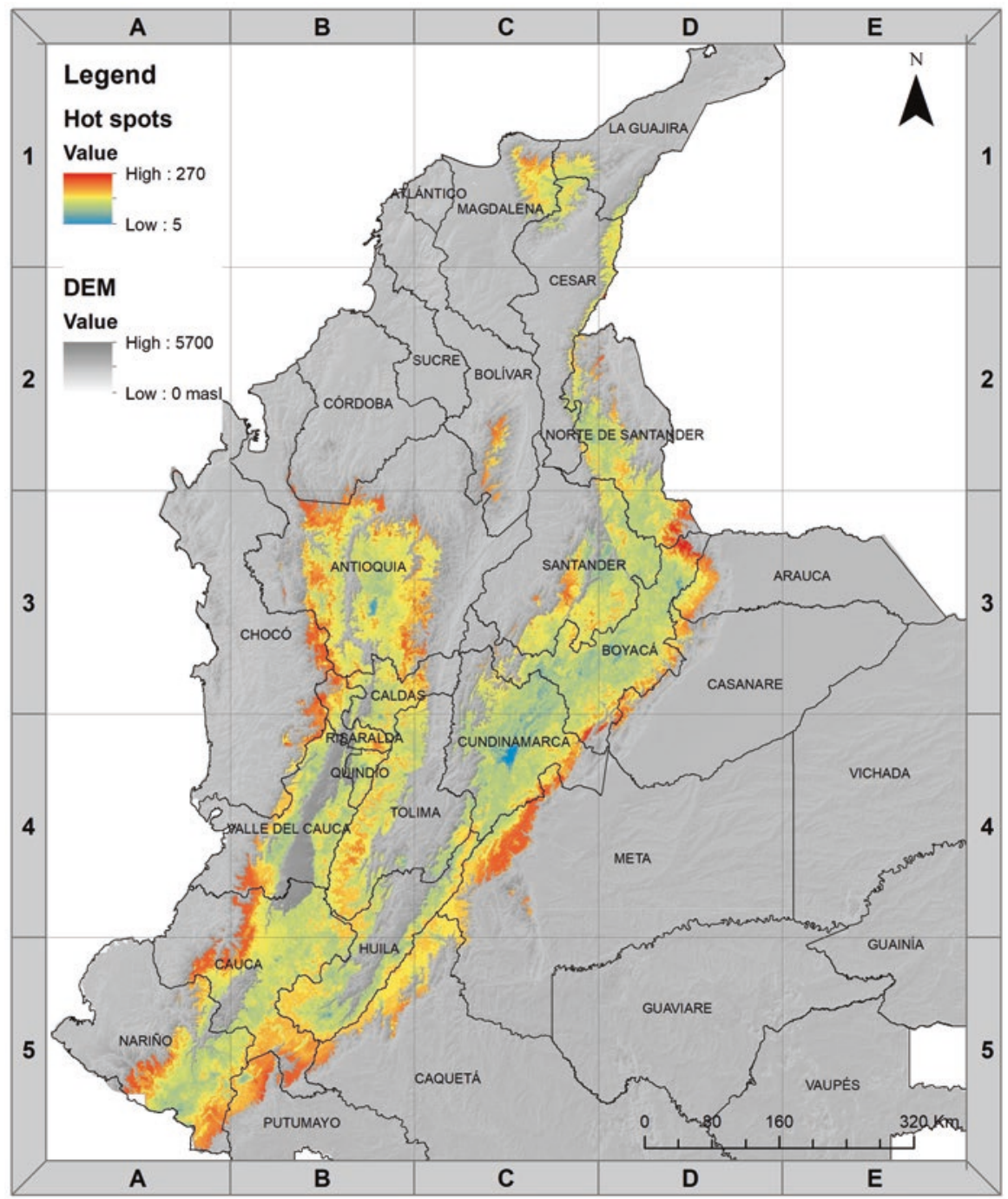

Fig. 3.11 Mapa de hotspots de servicios de carbono, oferta y regulación hídrica 


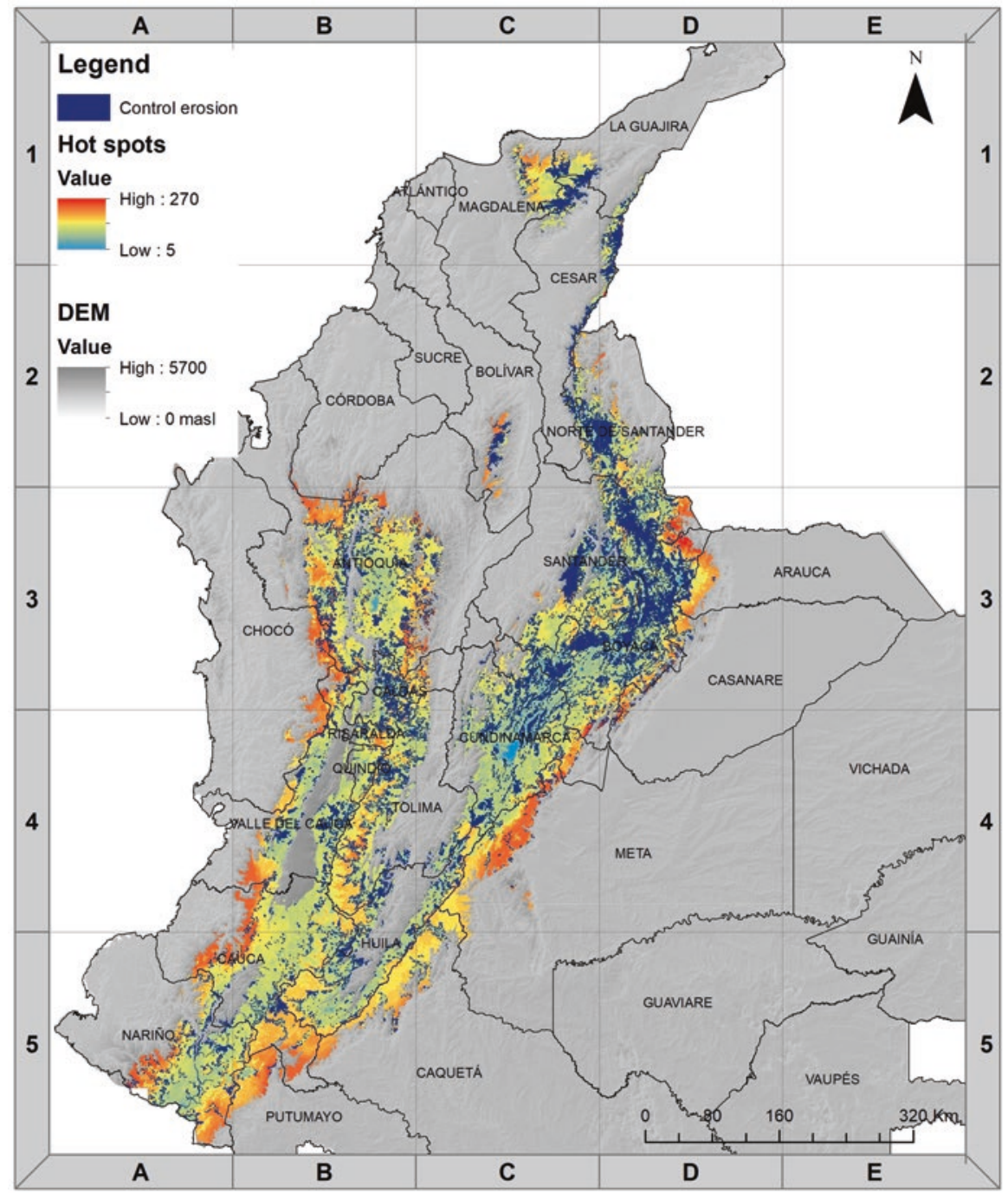

Fig. 3.12 Áreas de control de erosión en coberturas vegetales en la montaña 


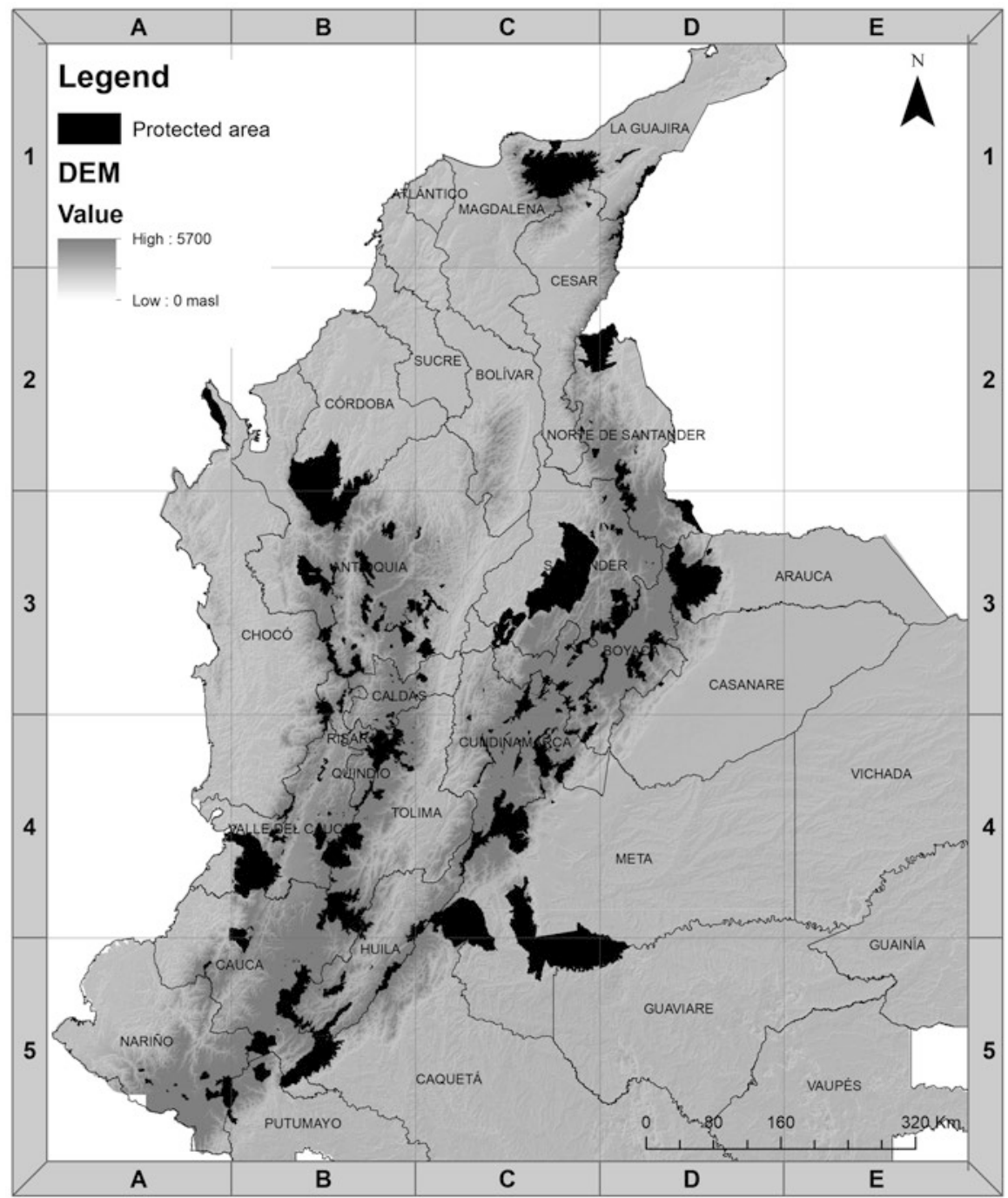

Fig. 3.13 Sistema Nacional de Áreas protegidas en zonas de montaña en Colombia 